\title{
Comprehensive Evaluation-Based Sports Network Transmission Way Innovation Research
}

\author{
HaiJun $\mathrm{Liu}^{1, *}$, Xueheng $\mathrm{Li}^{2}$ and Jingjing $\mathrm{Pei}^{3}$ \\ ${ }^{1}$ Department of Physical Education, Finance and Economics, Changchun, 130117, Jilin, China; ${ }^{2}$ Plaaf Aviation \\ University, Changchun 130000, Jilin, China; ${ }^{3}$ Institute of Physical Education, Jilin University, Changchun 130012, \\ Jilin, China
}

\begin{abstract}
Sports undertakings cannot develop without sports transmission influence, the transmission pervasiveness directly has the direct bearing on sports undertakings can be extensive spread among the whole nation or not. Research on sports network transmission innovation way is beneficial to impel sports undertakings development through utilizing advanced high technological means under new development situation. The paper carries out comprehensive analysis of Chinese sports transmission ways development, and makes comparison analysis of present stage sports media transmission ways on this basis, and further analyzes sports media transmission way of the highest public reliability. Utilize fuzzy comprehensive evaluation approach and analytic hierarchy process to make comprehensive evaluation on sports network transmission way, make quantitative analysis of sports network transmission innovation ways from the perspective of mathematics. Finally it presents that network sports transmission is of the highest weight among numerous sports network transmission ways, mobile television, mobile phone newspaper and other new media transmission public reliability is higher, which are most popular. Besides, network sports video, network sports news, and internet transmission are also the main ways that presently masses use to comprehend sports.
\end{abstract}

Keywords: Analytic hierarchy process, fuzzy evaluation, network transmission way, sports news, sports undertakings.

\section{INTRODUCTION}

Sports are a main way to enhance people physique and promote national cohesion. Sports extensive popularization in masses life not only can improve physical quality, mold character but also can improve people life's happiness index. Therefore, sports transmission issue becomes the key to sports development. Up to now, numerous scholars have done researches on sports transmission and achieved relative reliable conclusions [1].

Chen Yu-Zhong in the article " Modern sports transmission characteristics, values and its development orientation", through researching on modern sports, taking its characteristics, values and development orientations as research major goal, utilizing formers' research conclusions, and obtaining investigation data by interviewing with all sports institutions, handling and integrating data, while finally got conclusions [2]. The article presented that modern sports has gradually drawn close to high technological means, whose value not only reflected in boosting national sports undertakings development, but also had very important impacts on Chinese residents' life happiness degree [3-5].

Liu Xiao-Chun in the article "Chinese sports transmission industry characteristics and development countermeasures study", through researching on sports industry, he learnt Chinese sports industry characteristics and development trend [6]. The article researched sports transmission industry characteristics under Chinese national conditions from the perspective of present Chinese national conditions, and carried out practical investigation, collected data while handled and analyzed data, finally got the conclusion that Chinese sports transmission industry characteristics were multidirectional and globalization. Utilized network to rapid transmit Chinese sports culture while future Chinese sports transmission industry leading transmission trend was applying internet convenience, rapidness to let more people to know sports information and let more people to comprehend sports importance [7-9].

Jin Wen-Wen in the article "Sports transmission and national image shaping", took sports transmission and national image relations as main research direction, and further emphasized sports transmission importance through analyzing sports transmission impacts on national image. The article utilized multiple analytic methods, combined with lots of documents and collected data, carried out data analysis, and finally got the conclusion that sports transmission was a reflection that a country was leading in the information transmission or not, its transmission way was advanced or not, transmission effects were timely, correct or not, all of which were evaluation criterions to evaluate whether country was progressive in the high technological development or not, which played critical roles in a nation position and image in the world $[8,9]$.

The paper references lots of research results, and makes quantitative analysis of data, combines with mathematics 
fuzzy comprehensive evaluation approach and analytic hierarchy process to research on Chinese sports network transmission innovation ways, finally gets the conclusions.

\section{COMPREHENSIVE EVALUATION APPROACH'S SPORTS NETWORK TRANSMISSION WAY MODEL ESTABLISHMENT}

Sports development benefits from its transmission pervasiveness, sports transmission ways are quite a lot. With the development of economy, as well as continuous renewal of information technology, sports transmission ways also increase, and the transmission approaches also develop. All of them are of significance in Chinese residents' daily life.

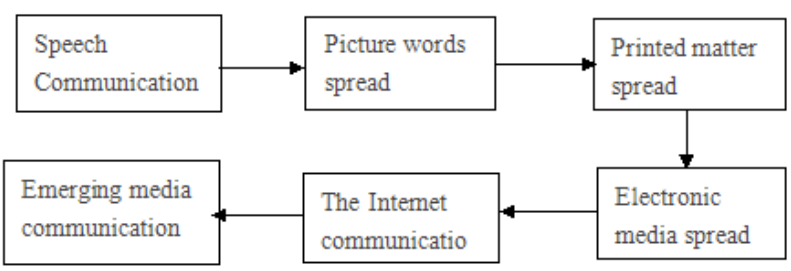

Fig. (1). The transmission way of the sports development.

Above Fig. (1) is Chinese sports transmission way development, from which the most original transmission way is speech communication, which is exchanging among people through the form of language. Secondly are picture words spread, radio and television transmission, internet transmission, emerging media communication including mobile phone newspaper, mobile television and so on.

As emerging media, mobile phone media, from which it mainly includes mobile television, mobile phone newspaper, mobile phone video live broadcast and so on, are more and more popular and gradually become vigorous impetus to advance sports transmission development and are major goal in future stage Chinese sports transmission developing.

Below Table $\mathbf{1}$ is analytic investigation on several kinds of sports transmission ways reliability from Chinese masses, data is from general administration of sport of China, internet relative investigation sorting results. (2).

Sort out above data, draw it into following statistical Fig.

At present, Chinese sports industry development suffers multiple aspects influences, whose development is rather slow by comparing to developed countries. Among them, imperfect sports industry management system imperfect, not profound public sports consciousness, not extensive sports transmission and others are main factors that restrict Chinese sports development.

Among numerous media transmission ways, network and cell phone are most popular media transmission ways, their reliabilities are the highest, secondly is broadcast, newspaper, television and so on. It indicates that for emerging media transmission ways, cell phone and network are the leading in future stage sports transmission development, whether them can be widely applied into masses life or not is one of the key factors to develop Chinese sports, and is also the active force to impel Chinese sports undertakings.

\subsection{Define Evaluation Indicator Set}

According to lots of document literature, it is clear that sports transmission network transmission ways are mainly network sports news, internet transmission, network sports video, network sports live broadcast, mobile phone newspaper, and mobile television, according to:

$U=\left\{u_{1}, u_{2}, \cdots, u_{m}\right\} m=1,2,3, \cdots, 6$

Evaluation indicator set is $=$ \{network sports news, internet transmission, network sports video, network sports live broadcast, mobile phone newspaper, and mobile television $\}$.

\subsection{Define Evaluation Grade Set}

For system evaluation grade, main defining method is expert evaluation approach. In sports transmission network transmission ways evaluation, its evaluation grade set is as following, according to:

$V=\left\{v_{1}, v_{2}, \cdots, v_{n}\right\}, n=1,2,3,4$

Table 1. Most popular sports transmission ways.

\begin{tabular}{|c|c|c|c|c|c|c|c|}
\hline \multirow{2}{*}{ Item } & \multicolumn{7}{|c|}{ Media } \\
\cline { 2 - 8 } & Newspaper & Television & Broadcast & Magazine & Cell phone & Network & Books \\
\hline \hline Percentage $\%$ & $16.5 \%$ & $9.9 \%$ & $11.3 \%$ & $10.9 \%$ & $10.9 \%$ & $32.1 \%$ & $8.4 \%$ \\
\hline
\end{tabular}

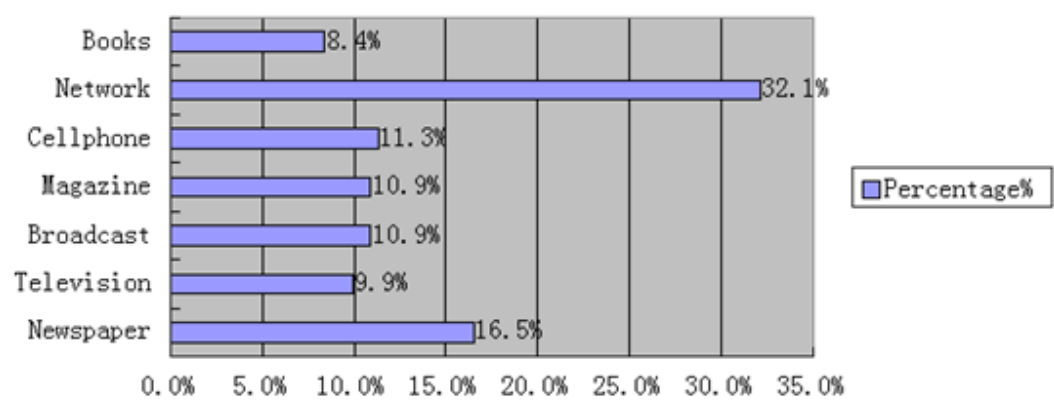

Fig. (2). The most popular sports dissemination way. 
Sports network transmission way evaluation grade set is $=$ \{very good, good, general, poor\}.

\subsection{Define Each Evaluation Indicator Weight}

Weight main expression method is :

$w=\left\{\mu_{1}, \mu_{2}, \cdots, \mu_{m}\right\} m=1,2, \cdots, 6$

Among them: $\sum_{m=1}^{6} \mu_{m}=1$

Define evaluation indicator weight method mainly has analytic hierarchy process and normalization method, from which normalization formula is as following :

$$
w_{i}=\frac{\frac{C_{i}}{\overline{S_{i}}}}{\sum_{i=1}^{n} \frac{C_{i}}{\overline{S_{i}}}},(i=1,2, \cdots, m)
$$

Among them, $w_{i}$ is evaluation parameter $i$ monitoring value; $\overline{S_{i}}$ is evaluation parameter $i$ grade $m$ criterion arithmetic average value, then weight set is:

$$
w=\left\{w_{1}, w_{2}, \cdots, w_{m}\right\}
$$

Here, apply normalization method to calculate weights, result is :

$$
w=\{0.06, \quad 0.04, \quad 0.15, \quad 0.30, \quad 0.20, \quad 0.25\}
$$

\section{DEFINE EVALUATION MATRIXES}

Comprehensive evaluation matrix $R$ evaluation methods mainly have expert evaluation method, analytic hierarchy process, and membership function method.

In above three methods, expert evaluation method is based on questionnaire survey and experts' evaluation result statistics, the result will have certain errors. So to let computed result to be more accurate, here uses analytic hierarchy process, define fuzzy relation matrix $R$, from which:

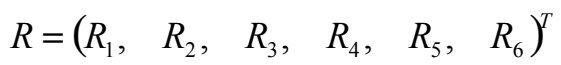

\subsection{Analytic Hierarchy Process-Based Sports Network Transmission way Comprehensive Evaluation Matrixes}

Due to sports network transmission way has network sports news, internet transmission, network sports video, network sports live broadcast, mobile phone newspaper, and mobile television these six types, now carry out analytic hierarchy process on them.

a. Target layer: Sports network transmission way evaluation

Criterion layer: Scheme influence factors, $C_{1}$ is timeliness, $C_{2}$ is accuracy, $C_{3}$ is convenience, $C_{4}$ is interaction.

Scheme layer: $A_{1}$ is very good, $A_{2}$ is good, $A_{3}$ is general, $A_{4}$ is poor and then it gets Fig. (3).

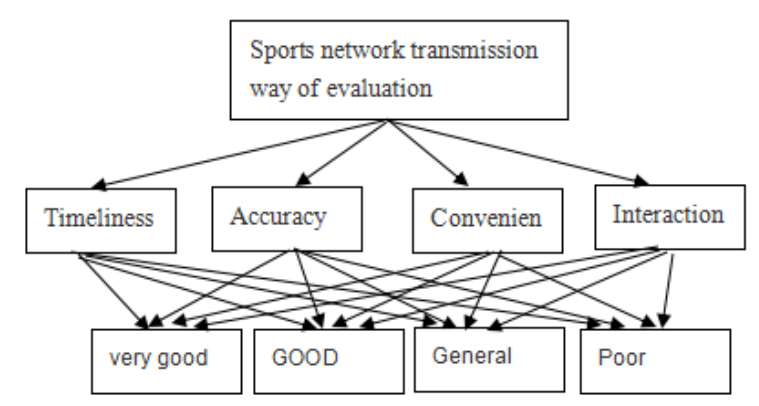

Fig. (3). Class hierarchy.

b. Construct paired comparison matrix

Construct paired comparison matrix is carrying on paired comparison among elements, using matrix to express each layer every element importance to previous layer all elements, here apply operational research expert proposed $1 \sim 9$ ratio scale Table 2 .

Table 2. 1 9 scale definition.

\begin{tabular}{|c|c|}
\hline Scale $a_{i j}$ & Definition \\
\hline \hline 1 & factor i and factor $\mathrm{j}$ have equal importance \\
\hline 3 & factor $\mathrm{i}$ is slightly more important than factor $\mathrm{j}$ \\
\hline 5 & factor $\mathrm{i}$ is relative more important than factor $\mathrm{j}$ \\
\hline 7 & factor $\mathrm{i}$ is extremely more important than factor $\mathrm{j}$ \\
\hline 9 & factor $\mathrm{i}$ is absolute more important than factor $\mathrm{j}$ \\
\hline $2,4,6,8$ & Indicates middle state corresponding scale value of \\
above judgments
\end{tabular}

According to above scale Table $\mathbf{2}$, set judgment matrix as:

$$
A=\left(\begin{array}{cccc}
1 & 3 & 3 & 3 \\
\frac{1}{3} & 1 & 5 & 5 \\
\frac{1}{3} & \frac{1}{5} & 1 & 1 \\
\frac{1}{3} & \frac{1}{5} & 1 & 1
\end{array}\right)
$$

And constructed scheme layer judgment matrixes correspond to different criterion layers are as following Tables 3 and 4.

c. Calculate weight

For

$$
A=\left(\begin{array}{cccc}
1 & 3 & 3 & 3 \\
\frac{1}{3} & 1 & 5 & 5 \\
\frac{1}{3} & \frac{1}{5} & 1 & 1 \\
\frac{1}{3} & \frac{1}{5} & 1 & 1
\end{array}\right),
$$


Table 3. Criterion layer judgment matrix $C_{1}$ and $C_{2}$.

\begin{tabular}{|c|c|c|c|c|c|c|c|c|c|}
\hline$C_{1}$ & $A_{1}$ & $A_{2}$ & $A_{3}$ & $A_{4}$ & $C_{2}$ & $A_{1}$ & $A_{2}$ & $A_{3}$ & $A_{4}$ \\
\hline \hline$A_{1}$ & 1 & 3 & 3 & 5 & $A_{1}$ & 1 & 3 & 3 \\
\hline$A_{2}$ & $1 / 3$ & 1 & 4 & 4 & $A_{2}$ & $1 / 3$ & 1 & 4 \\
\hline$A_{3}$ & $1 / 3$ & $1 / 4$ & 1 & 3 & $A_{3}$ & $1 / 3$ & $1 / 4$ & 1 \\
\hline$A_{4}$ & $1 / 5$ & $1 / 4$ & $1 / 3$ & 1 & $A_{4}$ & $1 / 5$ & $1 / 4$ & $1 / 3$ & 1 \\
\hline
\end{tabular}

Table 4. Criterion layer judgment matrix $C_{3}$ and $C_{4}$.

\begin{tabular}{|c|c|c|c|c|c|c|c|c|c|}
\hline$C_{3}$ & $A_{1}$ & $A_{2}$ & $A_{3}$ & $A_{4}$ & $C_{4}$ & $A_{1}$ & $A_{2}$ & $A_{3}$ & $A_{4}$ \\
\hline \hline$A_{1}$ & 1 & 2 & 3 & 3 & $A_{1}$ & 1 & 2 & 2 \\
\hline$A_{2}$ & $1 / 2$ & 1 & 3 & 3 & $A_{2}$ & $1 / 2$ & 1 & 3 \\
\hline$A_{3}$ & $1 / 3$ & $1 / 3$ & 1 & $1 / 3$ & $A_{3}$ & $1 / 2$ & $1 / 3$ & 1 \\
\hline$A_{4}$ & $1 / 3$ & $1 / 3$ & 3 & 1 & $A_{4}$ & $1 / 3$ & $1 / 3$ & 3 \\
\hline
\end{tabular}

Table 5. Random consistency indicator.

\begin{tabular}{|c|c|c|c|c|c|c|c|c|c|c|c|}
\hline$n$ & 1 & 2 & 3 & 4 & 5 & 6 & 7 & 8 & 9 & 10 & 11 \\
\hline$R I$ & 0 & 0 & 0.58 & 0.90 & 1.12 & 1.24 & 1.32 & 1.41 & 1.45 & 1.49 & 1.51 \\
\hline
\end{tabular}

firstly carry out following processing:

$\stackrel{\text { Column vector normalization }}{\longrightarrow}\left(\begin{array}{cccc}0.866 & 0.945 & 0.5 & 0.5 \\ 0.288 & 0.315 & 0.83 & 0.83 \\ 0.288 & 0.063 & 0.167 & 0.167 \\ 0.288 & 0.063 & 0.167 & 0.167\end{array}\right)$

$\stackrel{\text { According to the row sum }}{\longrightarrow}\left(\begin{array}{l}2.811 \\ 2.263 \\ 0.685 \\ 0.685\end{array}\right) \stackrel{\text { The normalized }}{\longrightarrow}\left(\begin{array}{l}0.703 \\ 0.566 \\ 0.171 \\ 0.171\end{array}\right)=W^{0}$

Then, by $A \times W^{0}=\left(\begin{array}{l}0.703 \\ 0.566 \\ 0.171 \\ 0.171\end{array}\right)$ it further solves

$\lambda^{0}{ }_{\max }=4.242$.

Similarly, criterion layer judgment matrix corresponding maximum feature value and feature vector are successively:

$$
\lambda^{(1)}{ }_{\max }=2.874, \omega_{1}^{1}=\left(\begin{array}{l}
0.883 \\
0.413 \\
0.140
\end{array}\right)
$$

d. Consistency test
Consistency indicator: $C I=\frac{\lambda_{\max }-n}{n-1}$

Random consistency indicator: Generate multiple matrixes at random, add every matrix consistency indicator and then take average value and get Table $\mathbf{5}$.

Consistency rate: If $C R=\frac{C I}{R I}<0.1$, constructed paired comparison matrix $A$ passes consistency test.

By above steps computed results, it is clear that paired comparison matrix maximum feature value $\lambda_{\text {max }}=4,242, R I=0.90$.

By consistency indicator $C I=\frac{\lambda_{\max }-n}{n-1}$, input data and calculate then it gets $C I=\frac{4.242-4}{4-1}=0.081$.

And according to consistency rate $C R=\frac{C I}{R I}=\frac{0.081}{0.90}=0.089<0.1, \quad$ so constructed paired comparison matrix $A$ passes consistency test. Similarly, it can verify that criterion layer judgment matrixes also pass consistency test.

Thereupon, it can calculate weight is : 


$$
\begin{gathered}
W_{1}=\left(\begin{array}{l}
0.1 \\
0.3 \\
0.5 \\
0.1
\end{array}\right) W_{2}=\left(\begin{array}{l}
0.2 \\
0.3 \\
0.4 \\
0.1
\end{array}\right) ; W_{3}=\left(\begin{array}{l}
0.2 \\
0.25 \\
0.5 \\
0.05
\end{array}\right) ; W_{4}=\left(\begin{array}{l}
0.05 \\
0.4 \\
0.45 \\
0.1
\end{array}\right) ; \\
W_{5}=\left(\begin{array}{l}
0.1 \\
0.3 \\
0.4 \\
0.2
\end{array}\right) ; W_{6}=\left(\begin{array}{l}
0.2 \\
0.35 \\
0.35 \\
0.1
\end{array}\right)
\end{gathered}
$$

\subsection{Comprehensive Evaluation Matrix}

By above calculation result, it is clear:

$$
\begin{gathered}
R_{1}=\left(\begin{array}{l}
0.1 \\
0.3 \\
0.5 \\
0.1
\end{array}\right) ; \quad R_{2}=\left(\begin{array}{l}
0.2 \\
0.3 \\
0.4 \\
0.1
\end{array}\right) ; \quad R_{3}=\left(\begin{array}{l}
0.2 \\
0.25 \\
0.5 \\
0.05
\end{array}\right) ; \quad R_{4}=\left(\begin{array}{l}
0.05 \\
0.4 \\
0.45 \\
0.1
\end{array}\right) ; \\
R_{5}=\left(\begin{array}{l}
0.1 \\
0.3 \\
0.4 \\
0.2
\end{array}\right) ; \quad R_{6}=\left(\begin{array}{l}
0.35 \\
0.35 \\
0.1
\end{array}\right)
\end{gathered}
$$

And further by, it can get comprehensive evaluation matrix as following:

$$
R=\left(\begin{array}{cccccc}
0.1 & 0.2 & 0.2 & 0.05 & 0.1 & 0.2 \\
0.3 & 0.3 & 0.25 & 0.4 & 0.3 & 0.35 \\
0.5 & 0.4 & 0.5 & 0.45 & 0.4 & 0.35 \\
0.1 & 0.1 & 0.05 & 0.1 & 0.2 & 0.1
\end{array}\right)
$$

\subsection{Make Comprehensive Evaluation}

$$
\begin{gathered}
\text { Known } W=\left(\mu_{j}\right)_{1 \times m}, R=\left(r_{j i}\right)_{m \times n} \text {, by } \\
S=w \circ R=\left(\mu_{1}, \mu_{2}, \cdots, \mu_{m}\right) \circ\left(\begin{array}{cccc}
r_{11} & r_{12} & \cdots & r_{1 n} \\
r_{21} & r_{22} & \cdots & r_{2 n} \\
\vdots & \vdots & \vdots & \vdots \\
r_{m 1} & r_{m 2} & \cdots & r_{m n}
\end{array}\right)=\left(s_{1}, s_{2}, \cdots, s_{n}\right)
\end{gathered}
$$

It can get fuzzy evaluation set $S$, from which“० " is fuzzy composition operator. Here take fuzzy operator as operator $M(\cdot, \oplus)$, that:

$$
s_{k}=\min \left(1, \sum_{j=1}^{m} \mu_{j} r_{j k}\right), k=1,2, \cdots, n
$$

Input above computed result into above formula, it can get:

$$
S=\left(\begin{array}{llllll}
0.136, & 0.103, & 0.221, & 0.441, & 0.298 & 0.321
\end{array}\right)
$$

By analyzing fuzzy evaluation vector $S$, it makes comprehensive conclusion. Generally, it can adopt maximum membership principle, weighted average principle, fuzzy vector uniformization, and here apply maximum membership principle.

For maximum membership principle, if given fuzzy evaluation set $S=\left(S_{1}, S_{2}, \cdots, S_{n}\right)$, (from which $S_{i}$ is grad $v_{i}$ to fuzzy evaluation set membership) $M=\max$ $\left(S_{1}, S_{2}, \cdots, S_{n}\right), M$, corresponding element is comprehensive evaluation result of evaluation.

By $S=\left(\begin{array}{lllll}0.103, & 0.298,0.321, & 0.441, & 0.221 & 0.136\end{array}\right)$, it is clear: $M=\max \left(S_{1}, S_{2}, \cdots, S_{n}\right)=0.441$

Therefore, in sports network transmission numerous ways evaluation, network sports transmission is the uppermost in sports network transmission numerous ways. Sports network transmission ways should consider timeliness, accuracy, convenience, interaction, comprehensiveness and so on, only information being timely and accurate then can attract more sports enthusiasts. Besides, other kinds of sports network transmission ways importance levels are in order: mobile television, mobile phone newspaper, network sports video, network sports news, internet transmission.

\section{SPORTS NETWORK TRANSMISSION WAYS COMPREHENSIVE EVALUATION}

\subsection{Network Sports Live Broadcast}

Network sports live broadcast is a way of most extensive application in present sports transmission and also most popular. With the development of internet, masses life focus has shifted from daily life to network life, more and more people exchange with outer world through internet, from qq chatting to international communication, all cannot do without internet. Sports as one of focuses in masses life discussion, its transmission also suffers network influences. Network sports live broadcast is the most direct and convenient way for masses comprehending sports and paying attention to sports games.

\subsection{Emerging Media Transmission Way}

At present, with the gradually development of economy, people's living standards obviously improve, mobile phone has become inseparable tool in people life. Therefore, mobile television, mobile phone newspaper, mobile phone video live and others become one of most popular media transmission ways. People use mobile phone to learn internet knowledge and pay attention to news and events.

Sports as one of Chinese development main evaluation indicators, its transmission also suffers great influences from network transmission. In recent years, most of sports enthusiasts use mobile phone newspaper, mobile television, mobile phone live and other ways to watch sports news, sports games, learn Chinese sports and world sports dynamic conditions.

\section{CONCLUSION}

The paper firstly researches on Chinese sports transmission ways development, and current stage most popular 
sports media transmission ways. Among them, sports transmission has gone through speech communication, picture words spread, radio and television transmission, internet transmission, emerging media transmission these ways. On this basis, compare with several kinds of transmission ways public reliability, and finally finds that mobile phone, network and other emerging media transmission public reliabilities are the highest and most popular, which is emerging active force to impel sports transmission, boost sports undertakings development in the future.

Secondly, the paper utilizes fuzzy comprehensive evaluation approach, carries out comprehensive evaluation on several kinds of sports transmission ways, makes quantitative analysis of sports transmission innovation ways from the mathematics perspective, and combines with analytic hierarchy process to construct comparison matrixes and improve evaluation accuracy. By calculation, finally it gets conclusions that network sports transmission is the highest weight in sports network transmission numerous ways, from which mobile television, mobile phone newspaper, network sports video, network sports news, internet transmission also account for larger proportions, which indicates emerging media sports transmission ways are sports transmission innovation ways that occupy the leading in sports transmission market and provides timely and reliable sports information for masses.

\section{CONFLICT OF INTEREST}

The authors confirm that this article content has no conflict of interest.

\section{ACKNOWLEDGEMENTS}

This work is supported by the Key Project of Guangxi Social Sciences, China (No. gxsk201424), the Education Science fund of the Education Department of Guangxi, China (No. 2014JGA268), and Guangxi Office for Education Sciences Planning, China (No. 2013C108).

\section{REFERENCES}

[1] L.U. Xu-tao, and H. Hong, "Survival and development of national traditional sports major under the background of globalization", Journal of Chengdu Physical Education Institute, vol. 37, no. 9, 2011.

[2] J. Zhao, "On the modernization dispute of national traditional sports", Sports Sciences Researches, vol. 15, no. 3, pp. 14-17, 2011.

[3] X-W. YE, "The cultural ecological perspective of heritage of national traditional sports", Bulletin of Sport Science \& Technology, vol. 19, no. 1, pp. 112-113, 2011.

[4] J. Zhao, and J. Wang, "Exploration of the way to the inheritance and development of traditional national sports", Journal of Physical Education, vol. 16, no. 8, pp. 93-95, 2009.

[5] R. Li, and C. Yu, "Sports globalization and descent of China traditional sports, Sports Culture Guide, vol. 4, pp. 84-86, 2007.

[6] L. Chen, "The research status and prospects of sport globalization at home and abroad", Sports \& Science, vol. 30, no. 4, pp. 54-56, 2009.

[7] L. Guo, "Studies of the ways of inheriting and passing on of the ethnic traditional sports in China", Journal of Southwest China Normal University (Natural Science), vol. 33, no. 6, pp. 157-160, 2008.

[8] Y. Hu, "Cultural confusion and coping mechanism of martial arts in context of globalization", Journal of Shenyang Sport University, vol. 28, no. 4, pp. 110-113, 2009.

[9] G. Wang, "Concerns of national traditional sports: current status, problems and reflections", Journal of Capital College of Physical Education, vol. 20, no. 2, pp. 1-4, 2008.

Received: June 10, 2015

Revised: July 29, 2015

Accepted: August 15, 2015

(C) Liu et al.; Licensee Bentham Open.

This is an open access article licensed under the terms of the (https://creativecommons.org/licenses/by/4.0/legalcode), which permits unrestricted, noncommercial use, distribution and reproduction in any medium, provided the work is properly cited. 